Ambiances

anbiances Environnement sensible, architecture et espace urbain

7 | 2021

Staging Atmospheres: Theatre and the

Atmospheric Turn - Volume 2

"Mother and son: Reality versus art in virtual reality. Staging an atmospheric performance with immersive technologies"

"Mère et fils : La réalité face à l'art en réalité virtuelle. Mettre en scène une performance atmosphérique avec les technologies immersives"

Maxime Le Calvé

OpenEdition

Journals

Electronic version

URL: https://journals.openedition.org/ambiances/4025

DOI: $10.4000 /$ ambiances. 4025

ISSN: 2266-839X

Publisher:

Direction Générale des Patrimoines - DAPA - MCC, UMR 1563 - Ambiances Architectures Urbanités $(\mathrm{AAU})$

Electronic reference

Maxime Le Calvé, "'Mother and son: Reality versus art in virtual reality. Staging an atmospheric

performance with immersive technologies"'", Ambiances [Online], 7 | 2021, Online since 22 December 2021, connection on 24 December 2021. URL: http://journals.openedition.org/ambiances/4025 ; DOI: https://doi.org/10.4000/ambiances.4025

This text was automatically generated on 24 December 2021.

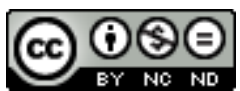

Ambiances is licensed under a Creative Commons Attribution-NonCommercial-NoDerivatives 4.0 International License. 


\title{
"Mother and son: Reality versus art in virtual reality. Staging an atmospheric performance with immersive technologies"
}

\author{
"Mère et fils : La réalité face à l'art en réalité virtuelle. Mettre en scène une \\ performance atmosphérique avec les technologies immersives"
}

Maxime Le Calvé

The virtual reality artwork Mother and Son: Reality versus Art. (The A.V.E.N.I.R. of Infinity) is presented at the Berliner Festspiele as part of the Immersion programme. ${ }^{1} \mathrm{~A}$ space has been set up for it in a gallery on the first floor of the Gropius Bau, a large and prestigious museum space in downtown Berlin. Announced as a performance, this piece is co-produced by the ARTE channel, announced and broadcast on their website dedicated to immersive media. On the Berlin institution's website, the public can already buy their tickets and reserve a time slot. That afternoon, I go to the opening, an exclusive event for a limited number of guests. The usual speeches are kept fairly short, with the usual exchange of acknowledgements for the production and the artist. A large white box of plywood has been assembled inside the museum space. A small queue forms along its side. A member of the museum staff tells us to wait at the entrance, which is kept shut by a black curtain. I peek through a little gap: inside, five spectators are sitting on stools, wearing masks equipped with Head Mounted Displays (HMDs), also commonly named Virtual Reality (VR) headsets. They are experiencing a performance by the artist Jonathan Meese. Another staff member is watching out inside the box. He is the one who hands me the VR equipment when my turn has come. It is a stand-alone headset, which does not need to be connected to a computer. This model is suitable for viewing $360^{\circ}$ immersive videos, which is the technology used by ARTE for most of their other VR experiences on their website and mobile app. The experience is also available online, and audiences can immerse themselves in it from their living room or office - which is what I invite the reader to do - all they need is to click on 
the link from whatever device they are using while reading this digitally published paper - although only a headset or a recent smartphone with a cardboard mount can provide an actual sense of immersion in the scene. ${ }^{2}$

Imagine that you devote several years of fieldwork to studying the artistic activity of a famous contemporary artist: following him, describing his ways of doing and being at length with hundreds of pages of field notes, photographs and drawings. By conceptualizing the notion of atmosphere, you manage to provide a satisfactory description of what happens in his team and in contact with his audience - but you can never take your reader to the creative phenomenon, at the heart of the artist's process. Suddenly you are told that this artist is going to create a work in virtual reality produced by the ARTE channel and one of Berlin's major institutions specializing in immersive artworks. In it, he will stage his creative process and the intimate sphere of his relationship with the person who puts him to work: his own mother. As an ethnographer, this gives you a bit of a jolt. A re-enactment filmed in $360^{\circ}$, directed by the artist himself, surrounded by an expert team, seems like a perfect opportunity to take a lesson in multi-sensory documentation - and to explore the possibilities offered by this emerging medium. The production team is commissioning me to make a series of ethnographic drawings about the production process of this work. This is an opportunity to describe the theatrical object in the making, and not simply to analyse a finished work - and thus to formulate the rudiments of the aesthetic of a VR atmospheric production based on a case that I am deeply familiar with.

The ethnography of the making of a work in virtual reality is an opportunity to observe the way in which the different actors in the production chain open up the possibilities offered to capture and stage an atmosphere - through scenography, action in front of the camera, editing, and effects capable of restoring sensitive presences. Theatre studies has recently opened up to the study of these phenomena of presence "in the making." With the emergence of post-dramatic theatre (Lehmann, 2006), the action takes place elsewhere than in the text and its representation. The analyses shift the focus away from the text or the staging-as-text, thus less on the semiotics intentionally deployed by a demiurge director and author, than on the performance itself, i.e. the effects on the researcher-observer affected by the different media of the theatrical action, the actors' bodies, the materials of the stage designs and costumes, the lighting effects, and most of all, the interaction with the audience. The book by Erika FischerLichte that really marks this turning point in German theatre studies (2004) focuses on the 'transformative' effects of theatrical performance, both on the actors and on the audience. Two important conceptual elements of this seminal theoretical approach are the attention to the "bodily co-presence" of spectator and actor (ibid., p. 38-74), as well as the "atmospheric force of performance" formulated by Gernot Böhme (ibid., p. 114-120). With this new emphasis on phenomenology, theatre analyses are fundamentally renewed in their practice. Furthermore, new forms of contemporary theatre emphasize the dynamics at work during rehearsals, sometimes presenting actors as staging the creative process, with its improvisations, doubts, and more precarious aesthetics, to the audience (Hinz and Roselt, 2011). The production process is thus gradually becoming an important site of ethnographic investigation into the production of works - not only in theatre, but also in contemporary art in the context of relational and participatory art approaches. 
4 In the field of anthropology, ethnography and participant observation are used to describe this type of creative process. The ethnography of western contemporary theatrical and artistic performances, despite the pioneering work of Richard Schechner (1985), is still a relatively marginal field. ${ }^{3}$ Yet, as Fiona Siegenthaler points out, ethnography is a particularly relevant mode of enquiry for highlighting the factors that can make participatory artworks explicit, in both their aesthetic and ethical gestures (Siegenthaler, 2013). In this case, we will describe how professionals collaborate together in order to elicit and capture an atmosphere and make it perceptible to a distant viewer in time and space: the artist himself and his mother, with their presence and performance, the playwright with his ways of making the story more effective, the director with his script and his ways of directing the ensemble, the lighting engineer and his spotlights, the sound engineer and his microphones, the make-up artist and her foundations, the technicians who prepare/stage the set, the production managers and assistants who provide practical and institutional stability to the whole, the cameraman who films the making of the film - and of course, the ethnographer who draws the scenes that will become the subject of an academic article.

5 I will begin by presenting this performance in virtual reality through the account of my experience as a spectator. I will then proceed with sketching the backdrop of this artistic production, in order to situate Jonathan Meese and his work, the team that supports him and their institutional entanglements. This will be followed by a reflection on how this project came into being. The second part of the article will be focused on the technical making of the work, with an introduction to this immersive technology, paying particular attention to on its capacity to render atmospheric and theatrical phenomena, and second, an ethnographic account of the production of this performance in VR, based on a series of drawings. In concluding remarks, I will highlight what the specific component of VR in this singular performance brings us to understand about the manifold ways in which production process of the performance and its underlying atmospheric dimension get articulated together through an entangled process of translations and negotiations.

\section{Describing a VR performance from inside the HMD}

6 A quick note about the following section: the writing here was done according to the "memory protocol", a method of phenomenological description invented by researchers in theatre studies to collect the main elements of their experience of a theatrical or performance work. ${ }^{4}$ Unlike a conventional ethnographic process, no notes are taken on the spot at the time of the event - this would be counterproductive to the immersion necessary to grasp the sensitive phenomenon in its entirety. The "memory protocol" invites the researcher to let some time pass before starting to write: not the same evening but the next morning. This process has been developed in particular for performances in which the spectator is called upon to take an active part in the theatrical dispositive. Here, the method is particularly suitable since no notes can be taken immediately while wearing a VR headset. The medium of the video obviously makes it possible to detail the work afterwards, but that is not the approach I have chosen here. I am more interested in the viewer's sensory experience than in a semiotic analysis of the work - and in particular the capacity of the virtual reality medium to capture and shape the atmosphere of a situation. 
7 I take a seat on one of the stools. In one corner of the room, I can see a small green armchair and a bed undone. A boombox sits in the corner, silent. The white walls are scrawled with red paint. The lines show a lively energy and as I am already familiar with the artist, I can recognize some symbols belonging to his usual vocabulary. The presence of four other human beings sitting relatively close in the room is also quite strong, overpowering the atmosphere of the otherwise very simple set - perhaps a weakness of the installation.

Back to the exhibition space. I'm putting on the helmet which was handed to me - the blackout is almost complete. A title screen appears. Then I find myself in the same 'box,' alone this time. The walls, however, are entirely white. The room is completely empty except for the bed, an armchair, a robotic toy on the floor, a child's lamp in the shape of a Moomin ${ }^{5}$ and the boombox. There is someone in the bed: Jonathan Meese appears to be having a restless dream - or more precisely, giving us a cheap act of a feverish sleep. A scene materializes behind me, I am alerted by the sound and turn my head into that direction. I see a second avatar of the artist, tied up with a rope, jumping around in slow motion trying to catch sausages with his mouth. These sausages are suspended above him, moving as if someone is holding them with invisible threads. This scene, strange and ambivalent, is rather wryly funny - the artist is being silly. After a few seconds, the scene disappears again into the ether, from where it had come. There is a knock on the door. The face of Brigitte Meese, an elderly woman in her eighties, appears in the doorway-'it's time to wake up,' she says. She enters the room with two large cups of coffee. 'Good morning, it's time to wake up' 'Cool,' says the artist. 'I didn't put sugar in, it's not good for your health.' She sits down on the green armchair, while her son is still wallowing, fully clothed in that little bed on the floor. He hands her a paperback, 'Golden ladies, my favourite book' he says. She replies to this that she prefers 'Room Number 13 ' ... a short morning chat ensues. 


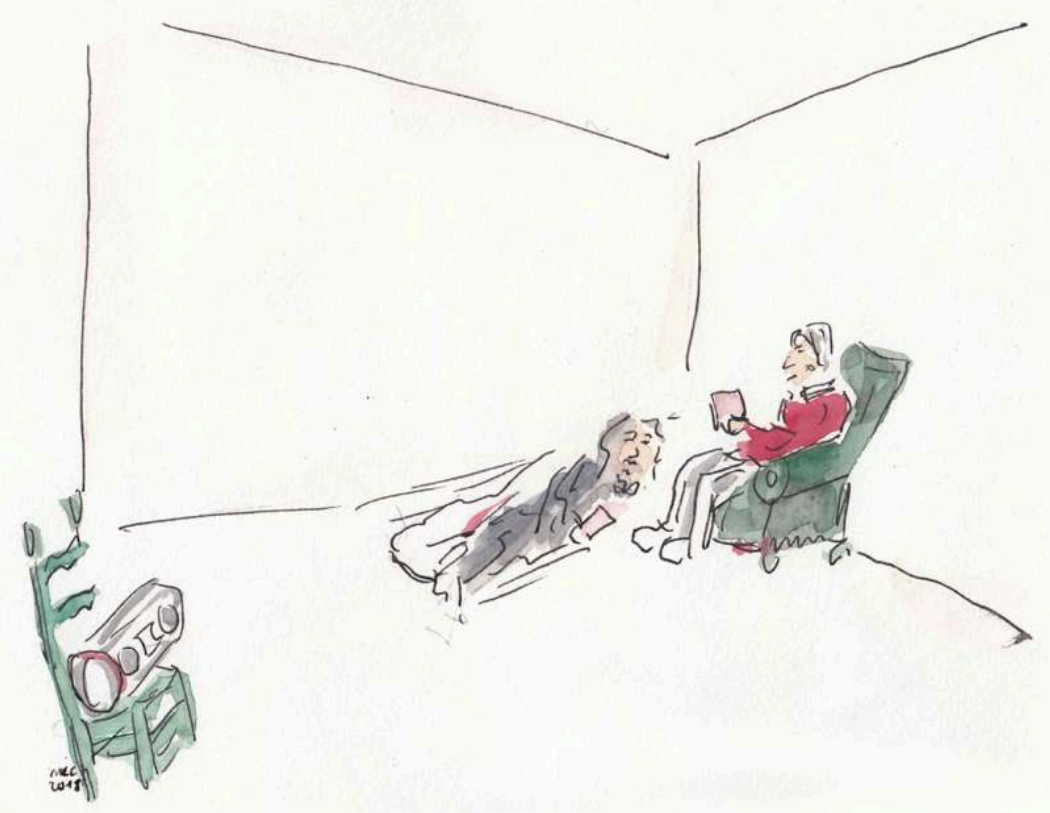

Credit: Maxime Le Calvé

9 A second Brigitte Meese enters through the door with a can of paint and a brush: 'It's time to work,' she says. 'It's time to paint.' The first Brigitte remains seated in the green armchair, watching the second, unmoved with the apparition. Meese is willing to comply 'I think I'm going to start, I really want to paint. That's what art is, you have to go for it without thinking.' He grabs the brush, dips it in the pot, and embarks on an action painting sequence. 'It goes by itself' - the artist speaks as he paints, with a first scrawl. The viewer recognizes the inscriptions on the walls of the box, red on white: it is the recorded sequence that gave rise to the work that is now being replayed in front of them. A number appears in the course of the brush stroke: 'Five is great, look, what do you think, Mama?' 'I think it's not really finished yet' 'but wait, look, five again, and another five' 'It's better than Picasso, I think,' says the artist - the tone of voice doesn't say whether it's ironic or not, but the framing of the situation takes care of that for him. 'And here, the triangle is missing,' says Brigitte. 'Yes, okay,' says the artist, who immediately complies. 'And the square too.' We hear another knock on the door, the characters turn towards the entrance of the room, 'Look what I brought for you, a little reward,' says a third Brigitte, holding a lollipop in her hand. 'It's not finished, but okay. Don't eat too much, it's full of sugar. Is it good?' They are interrupted by a toy robot, which suddenly starts a little dance in the corner, 'what's that?' say the characters. The viewers ask themselves the same question: I found it hard to work out where this sound was coming from and what this impromptu event brings to the scene. We turn our heads again at the creaky noise of the door opening - another Brigitte is already inside the room, inserting a CD into the stereo. 'I even brought you some music' - she presses a button on the machine. Music blares into the room - not just any music, but music from the opera Mondparsifal, which Meese has staged the previous year in Vienna and Berlin. Only a small proportion of the audience will be able to recognize it - and I am one of them. The Wagnerian theme is vaguely identifiable, but the energetic saxophone 
improvisation is a sharp deviation from the original music. 'Acting acting acting, that's art.' The space is saturated with avatars of the mother gazing at her son, at the walls, slowly moving to the music.

A new Brigitte appears with a camera, she stands on one side of the room, and poses with her son on the other side - I find myself between the camera and the couple being photographed, which forces me to turn my head. So I am transparent! The artist dances again, obviously intending to leave his mark on the entire surface offered to him. A final avatar of the mother enters the room, holding what is perceived as an antique mirror. 'What is this, it's strange,' they say, meeting my eyes for the first time. The mother and son then hold up the mirror and bring it closer to me until an image becomes more distinct: instead of my face, I see that of the artist Meese dressed in a period costume and wearing a cardboard mask of Richard Wagner. I had been a mere invisible spectator until then - this shift causes a rather modest stir (are the characters aware of my presence or, more generally, that of the audience?), but I appreciate this change of regime in the experience. It reminds me of a phrase I read somewhere that the artist Meese "holds up a mirror" to those who are judging him. After this enigmatic appearance, the characters freeze and then fade away, the room is empty. A new inscription points to the exit: the word reality [Wirklichkeit] in large black letters. Then the end credits start, suspended in space: this is the moment when I pull out the VR headset. I contemplate the space around me again, the white walls with the red graffiti, the line I have just seen drawn. The small bed is unmade, and I notice other small details that I may not have seen when I entered, the Moomin, the paint can, etc. The experience lasted less than 10 minutes. It didn't feel too long. Four spectators, different from those that were there before, are sitting on their stools, silent and inexpressive, their faces hidden by their helmets. The person watching over us has noticed that I have entered our shared world of perception again and immediately comes to collect the technical equipment. I leave the room a little disheveled. Another person enters immediately behind me.

\section{Jonathan Meese: depicting an aura and its creative experience}




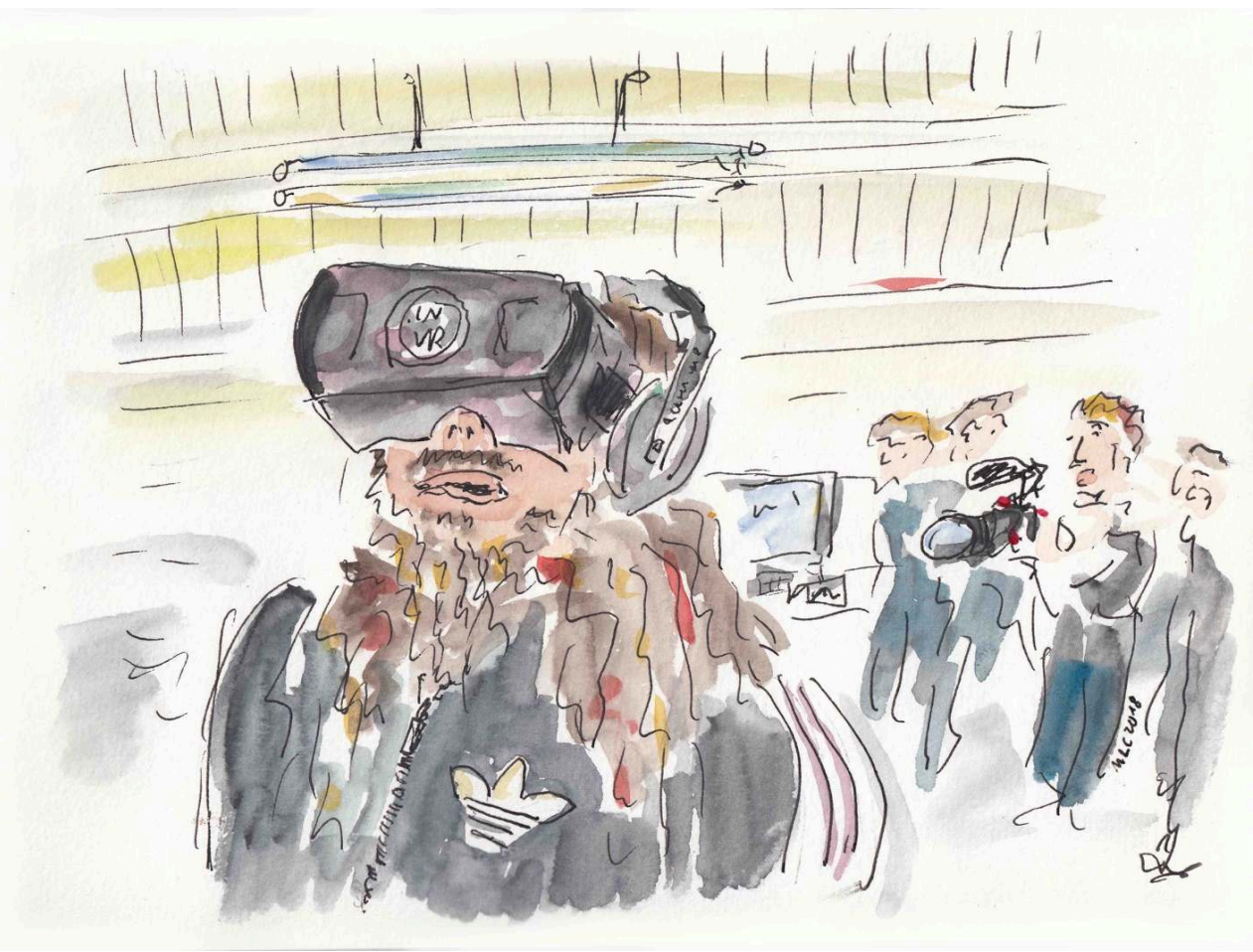

Credit: Maxime Le Calvé.

On the local scene, Jonathan Meese is a bizarre figure who is both notorious and odd. He has built himself a reputation as a controversial and polarizing figure. ${ }^{6}$ To the people I spoke to in the academic and art worlds, and to the vast majority of art enthusiasts I met in Berlin, Meese is a positively disturbing character, a singular personality who makes people think, laugh and talk, without taking himself too seriously. While I was initially apprehensive about meeting him, becoming part of the artist's team and the Berlin alternative scene quickly shifted me to the second group, that other perceptual world in which the artist's presence is felt as joyful and energizing. These observations are in line with those of many other theorists and authors who have approached the artist. This permanent performance - which, as the saying goes, lies "between art and life" - is of interest to both the theatre studies researcher and the ethnographer interested in the creative gesture.

Jonathan Meese, originally from the Hamburg area, has been living in Berlin since the early 2000s. Known primarily for his installations and the performances that accompany them, he is also an internationally renowned painter. His career reached a peak in popularity around 2007, which has since been maintained by regular media blitzes. The artist maintains this momentum by making his polemical persona the medium of a multimodal work. His performance practice also includes photography and video-a full-time collaborator produced a provocative photo diary of the artist's activities with the artist over a period of fifteen years, published on his website. The themes worked on - symbols of fascism, childhood and artistic creation, the artist as a servant of art, art as a tyrannical force pushing him to act - have remained relatively unchanged since his beginnings. He has a small team around him, including his mother who plays an important role in it and more generally in his work. 
13 Brigitte Meese plays her mommy role during the public appearances of the artist in a way that reinforces her son's perceived childishness. However, she is also important in the artist's creative process, since the artist has stepped out of the traditional system of a privileged relationship with a gallery. Brigitte has helped to build her son's new studio and bureau. On a day-to-day basis, she has long played a central role in the administration of the things the artist collects. She is also there to push him into action, along with the other women on the team. I have devoted several articles to this collaboration, on her role in establishing an atmosphere conducive to the artist's creative work (Le Calvé, 2015), on her activity in regulating the material collection activities maintained by her son (Le Calvé, 2017), and on her involvement in the elaboration of an antagonistic power play in the artist's image during his public performances (Le Calvé, 2018). She resides in an apartment in his house, in a central and meanwhile very fancy district of Berlin Mitte. They have breakfast together. She arranges the artist's objects, sorts through the colours, arbitrates decisions on the purchase of important supplies - the artist and the rest of the team know that this is a game, but one that she takes very seriously - or at least she has in the past, as her strength is failing her now, with old age coming. She encourages him, puts him under pressure to produce when the deadline approaches. In public, she is also a key figure in the relationship with some of the collectors, a reminder that her son's rantings are never to be taken totally seriously.

Meese's work on the theme of the "dictatorship of art" is conceived as an ongoing performance, a long-term investigation and a creative atmosphere. It is explicitly associated to his discourses with the loving atmosphere of the iconic mother-child relationship. To paraphrase a statement often repeated by the artist in his interviews (which systematically become performances, since Meese never gets out of character): "In the same way that the mother orders her son to go to bed, art orders the artist to get to work." Framing this posture with particularly successful situational irony, it is here the mother who orders the artist to get to work. This relationship - and the specific atmosphere attached to it - is staged without ever being completely false or a mere pretense, in the artist's speeches, performances, drawings and paintings, plays. In public or in private, when Meese paints, it is always part of that same process of the "dictatorship of art"-art literally and figuratively takes possession of the artist and sets him in motion. The paintings are the trace of this dance, they are the marks left behind by this phenomenon. Hermann Schmitz's concept of atmosphere is particularly useful here in breaking the analytical reflex that would make Meese the interpreter of an idea or concept (Schmitz, 2011). According to the philosopher, atmosphere is a force that passes through situations to imbue human beings and the objects around them with their sensible qualities: "feelings are atmospheres that spread through space and powers that seize carnally," he tells us (Schmitz, 2018, p. 51). The living body is the locus of receptivity to atmospheres, and describing Jonathan Meese's body as being put into action by art, or more precisely by the "dictatorship of art," provides us with an account that is more faithful to ethnographic observations - as well as to the artist's own account of his experience. By acting, talking and painting, and by playing his own character, the artist performs this specific atmosphere, he becomes its author without calling into question the fact that this force does not belong to him, that it comes from a constellation of images and presences which have been meticulously maintained around him. The artist works with the atmosphere, which is his ultimate material - and as such, he cannot clearly distinguish its influence from his own will. 
The VR performance we are interested in here is therefore just another way of triggering and presenting the crucial and comical drive of his work, in which this mother-son relationship plays an essential role.

\section{Virtual reality, a contemporary form of atmospheric theatre?}

15 When I think back to those filming days in 2017, I see Jonathan Meese with a VR headset on his head, viewing the scene he has just performed. He lets out a few cries of delight - he knows how to play with masks and he is well aware that he is being videotaped for the making-of. The production itself is a spectacle, a performance imbued with the technological and futuristic atmosphere of the VR medium.

16 Virtual reality is becoming increasingly popular. In recent years, major entertainment and information broadcasting platforms have been giving more and more space to this type of content (in particular the ARTE channel, or the Anglo-Saxon newspapers The New York Times and The Guardian, but also platforms specialized in the broadcasting of video games such as Steam). The shows on offer are also expanding to include live broadcasts of events captured by 3D and 360-degree cameras, with the ever-present argument of placing the viewer in the middle of the action, "as if you were there." I do not have the space here to review the state of the art of virtual reality research, but a short development is nevertheless necessary on the current state of affairs of this technology and on our relationship to these "present images" which are now becoming increasingly part of our "digital habitat" (Favero, 2018, p. 9).

VR activity has progressed in cycles since its invention. The term Virtual Reality is attributed to pioneer Jaron Lanier in 1989. Its definition created significant difficulties from the outset. Researchers wondered whether it should be defined by the type of technical apparatus it employs (the iconic "Head Mounted Displays" in particular) or by other more general principles or dimensions that determine immersion and presence in these virtual environments (Steuer, 1992). Defining its "essence" has triggered intense philosophical and metaphysical elaboration (Heim, 1994b; Brey, 2014). With the advent of a new generation of consumer devices, an intermediate definition seems to have been adopted: virtual reality has become a market that offers "on-demand" experiences (Bailenson, 2018). Interest waxes and wanes as technological innovations and possible applications emerge. VR is a new medium, and as such, it carries with it an atmosphere of innovation that institutions are eager to pursue. It is in this context that virtual reality is inviting itself everywhere, and more and more frequently in cultural institutions - in museums in particular - always keen on refreshing their image by riding new trends. But perhaps there is something more enduring here due to the particular aptitudes of this medium to stage atmospheres.

It is important to note that technical, institutional and economic aspects are intertwined in the current situation of the implementation of VR in art and theatre. According to the leading author on immersive digital arts, Oliver Grau, immersion is a visual phenomenon that has been sought after since antiquity, and the latest developments are to be seen as part of a continuous evolution of modes of visuality (Grau, 2003). The digital has become so labile and commonplace today that it has drastically altered the regime of existence of the image, moving from meaning to 
presence and co-presence (Favero, 2018, p. 10-11). In the field of virtual reality, a qualitative leap is explained by the release of the first headsets bringing these elements together around 2015 with the first Occulus headset (Stein, 2016; Woletz, 2018). The headset used in this performance, the Occulus Go, operates independently of a computer, and in particular allows $360^{\circ}$ videos to be viewed in a mobile way and at a reduced cost.

Technically, the possibilities are becoming more far-reaching - the definition and angle of view of the new capture and visualization equipment, as well as the computing power of the new machines, which make it possible to generate increasingly sophisticated graphics in real time, are opening up new creative possibilities that are particularly suited to the creation or transposition of atmospheres and situations. These developments are due to the maturation of technologies in other sectors, independently of these applications - hardware with the improvement of design, graphic processors, sensors and screens, but also economies of scale on these massproduced products; software with the spectacular improvement of tools for creating computer-generated images, notably driven by the field of industrial design, architecture and video games. Image quality, in particular, has improved considerably in recent years, driven by the continuing efforts of multinational companies to create increasingly mobile and powerful equipment. However, experts agree that, beyond a certain threshold (difficult to quantify), the experience of immersion and "presence" (or "telepresence") does not necessarily equate with the use of state-of-the-art equipment: the accuracy of the user's body tracking, in particular, is a crucial criterion for triggering that level of experience in which the person feels "there" in the virtual environment presented to them (Cummings and Bailenson, 2016). Other factors such as interactivity or storytelling are indeed as much if not more decisive than the quality of the image itself.

The arrival of these devices is announced as a revolution in many areas precisely because they are bringing new possibilities for instilling phenomena of presence and atmosphere for their users. Indeed, if the Occulus and other headsets that have since arrived on the market are presented as machines intended for entertainment, it is in other areas that the VR economic machine is currently in motion. This is evidenced by the large trade shows and conferences that attract sponsors and speakers from the largest global companies to present the new ways of consuming and producing that are being developed thanks to VR and other "spatial computing" technologies. The solutions presented have to do with a new vision: VR as a market, a new space to sell (think of architecture and urbanism - then forget that, think of everyday objects, your next sofa, your next shoes...); for training employees, from supermarket workers to neurosurgeons; for education, too, as these experiences can take schoolchildren on otherwise inaccessible field trips, and can provoke very high levels of attention and engagement with the teaching materials in some cases (Bailenson, 2018, chapter 4). And finally, to heal, with applications for people with various mental disorders, ranging from autism to dementia.

21 Is VR a medium conducive to the transmission of the sensory qualities of theatrical atmospheres? But is this theatre we are talking about? The philosopher Michael Heim, in his early book The Metaphysics of VR, has made a parallel with the musical drama and the Gesamtkunstwerk of Richard Wagner. He even goes so far as to put forward the idea that Parsifal and the Bayreuth Festival were the first virtual reality experiences (1994a, 
p. 127). Some theorists also suggest that VR is related to cinema, expanded further by computer graphics technologies (Youngblood, 1970; Goddard, 2021). All these analyses seem to agree that virtual reality can be posited as an in-between medium, particularly suited to providing the viewer with a sense of immersion. From a general perspective, however, the fact that the performance is recorded prohibits the manifestation of the phenomenon of 'radical presence' generated between actors and audience (FischerLichte, 2008, p. 77-78): the mere possibility that the performance changes its course through the intervention of the audience charges contemporary forms of theatre with an energy that is not reproducible through this type of technical mediation. As Erika Fischer-Lichte argues: "To the degree that performance attempts to enter the economy of reproduction, it betrays and lessens the promise of its own ontology." (ibid. p. 77). In the literature, however, VR has been documented by psychologists as showing strong potential to generate "presence" through the element of interactivity. (Cummings and Bailenson, 2016) This applies perhaps better to computer-generated images productions, which are more akin to the universe of the video game. As we have seen in this case, and more generally when the technology employed is $360^{\circ}$ video, the parameter of interactivity is reduced to the choice of a viewpoint, with a possibility to move the head from the inside of the spherical image - which is considered a minimal but convincingly effective way to produce the sensation of immersion into a virtual environment. On the other hand, this distinctive feature of VR brings up other difficulties: the minimal interactivity of the "choice of points of view" also causes other problems that counteract the effects of other "affective manipulation", particularly those related to storytelling. The VR medium poses real difficulties for those who want to tell stories, although the narrative factor remains high on the list of factors that allow the creation of experiences that work (Slater and Wilbur, 1997; Cummings and Bailenson, 2016). Contemporary forms of storytelling rely on controlled "arcs" which engage audiences through the recurrence of elements which become meaningful as the story unfolds. The freedom for viewers of choosing their point of view in VR implies either that this control of attention is exercised in an accentuated or exaggerated way by the director, or that other types of experiences must be adopted which are less related to these kinds of linear storytelling and favour other iterative or diffuse narrative modes. In this sense, the immersive device of VR points in the direction of the aesthetics of post-dramatic theatre: in the case I am presenting here, it is not the narrative of what is played out between the mother and the artist that is important, but rather certain qualities of the space born of their relationship.

As stated above, VR can allow a certain and ambiguous freedom of action and choice of perspective (at least that of directing the gaze) - the performance theorist Scott deLahunta has for this reason included it in the lineage of performance art (2002). It is indeed one of the major characteristics of this medium that it projects the spectators into the middle of the scene. It is called an immersion phenomenon: they have the possibility to turn her head and choose the element on which their attention is focused. As limited as this interaction with the scene may seem, this sharp difference from other media is particularly effective in giving the viewers a sense of presence, more so than the definition of the images themselves (Cummings and Bailenson, 2016; Stein, 2016). The term 'presence' is everywhere in the discourses of virtual reality experience designers (and promoters), and particularly when it comes to distinguishing their art from that of the 'flat' screen. 

versus Art. We will see that the performance of Meese is shaped by the technical possibilities of the medium: a sequence shot seems to catch the artist and the mother in their intimacy - although the white box setting and the slightly forced dialogue make it clear that the situation is being played out. The camera fades away, and the director decides to compose an artificial situation that amplifies the presence of the artist's mother by multiplying her in the image, by showing her in several postures at once. For the team, it was a matter of preparing a device in order to invite a phenomenon: the aura of a character and her working atmosphere. Throughout the making of the piece, it is also a question of inviting a virtual presence around which the whole device is fixed: the virtual spectators, what they will (or can) see through the eyes of the camera, understand and feel about what is happening there.

\section{The story of a VR production at Meese}

Observing the "workers of aesthetics" in action and witnessing the process of this work-in-progress first opens up the possibility of reporting on a technical process: the filming of a performance to make a $360^{\circ}$ video. In the classical manner of ethnology of techniques, these observations allow us to retrace the chaine opératoire ${ }^{7}$ of the fabrication of an atmosphere - or rather of the way that the artists and the atmospheres are mutually capturing each other, as I will try to make explicit below. I have not, however, chosen to give a systematic account of this chain, preferring to focus on a series of scenes which were selected on the fly during the fieldwork, each of them drawn and commented on as a study. This different way of recounting technical action aims to convey the sensitive experience of operations rather than the precise structure of their whole. I thus propose to focus, on the one hand, on the aesthetic experience offered by the technical performance of the VR shooting, and, on the other hand, on the atmospheric "translation" of a performance from one theatrical medium to another. The one obviously does not go without the other, the effects of mediation are embedded in each other: the technique "makes the actors and technicians do" all sorts of things (Latour, 1994) and it is through this new creative situation that the know-how of the artist and his team find a new chance to show their ability to make use of any opportunity - and to let themselves be carried away by their creative atmosphere by re-actualizing it.

The use of ethnographic drawing is a methodological commitment that continues to surprise me (just as Meese and his team are surprised by their art). Live drawing is also a technique of translation, whereby the atmosphere of the moment is transcribed and rendered manually, in an embodied act that combines observation and description (Causey, 2016). The anthropologist is thus in a position to transcribe the atmosphere of the situation in which they find themselves, through line and colour, practicing a specific type of phenomenography (Le Calvé and Gaudin, 2019). This autobiographical trace includes the qualities of the line itself, but also the composition of the images directly on site, and the storytelling that follows instantaneously from them - for this narrative was born out of the images, not the other way around. I see this story as a further transposition of Jonathan Meese's performance through my own experience a way of "thinking in atmosphere", as a "process of autoethnography conceived as a way of attending to and engaging thoughtfully with one's own emerging experiences to 
gain insight, including into the worlds of others." (Sumartojo and Pink, 2019, p. 70) This description is intended to situate the production of the work in its context, and in the multitude of processes and attention that allow the artist's atmosphere to be captured and staged. Let's now dive into the creative action.

Illustration 3: Ethnographic drawing of the main building of Jonathan Meese's studio

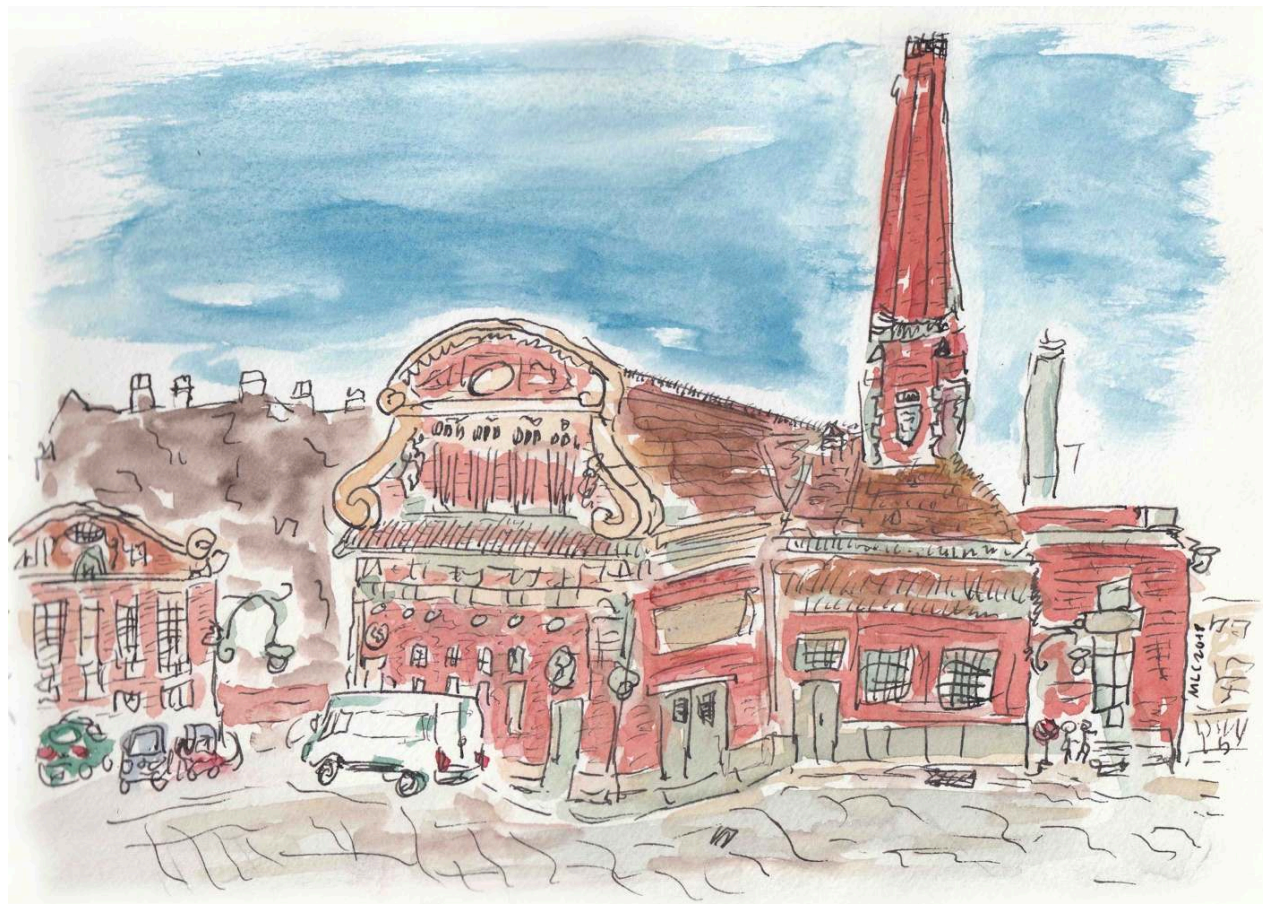

Credit: Maxime Le Calvé

February 2018. The filming takes place on the artist's premises, in his own studio. The artist's work space is located in the large hall of a complex of buildings in a northern district of Berlin that was purchased from the city a decade ago. The installation is part of the city's former water distribution system, the Radial System, and is protected as a historical monument. The huge chimney and the decorative elements of what was once a flagship of progress through machines makes it a perfect backdrop for the machine theatre that takes place inside. The morning briefing takes place in the annexe buildings, where the offices, the library and the kitchen are located. 
Illustration 4: The morning briefing around the model

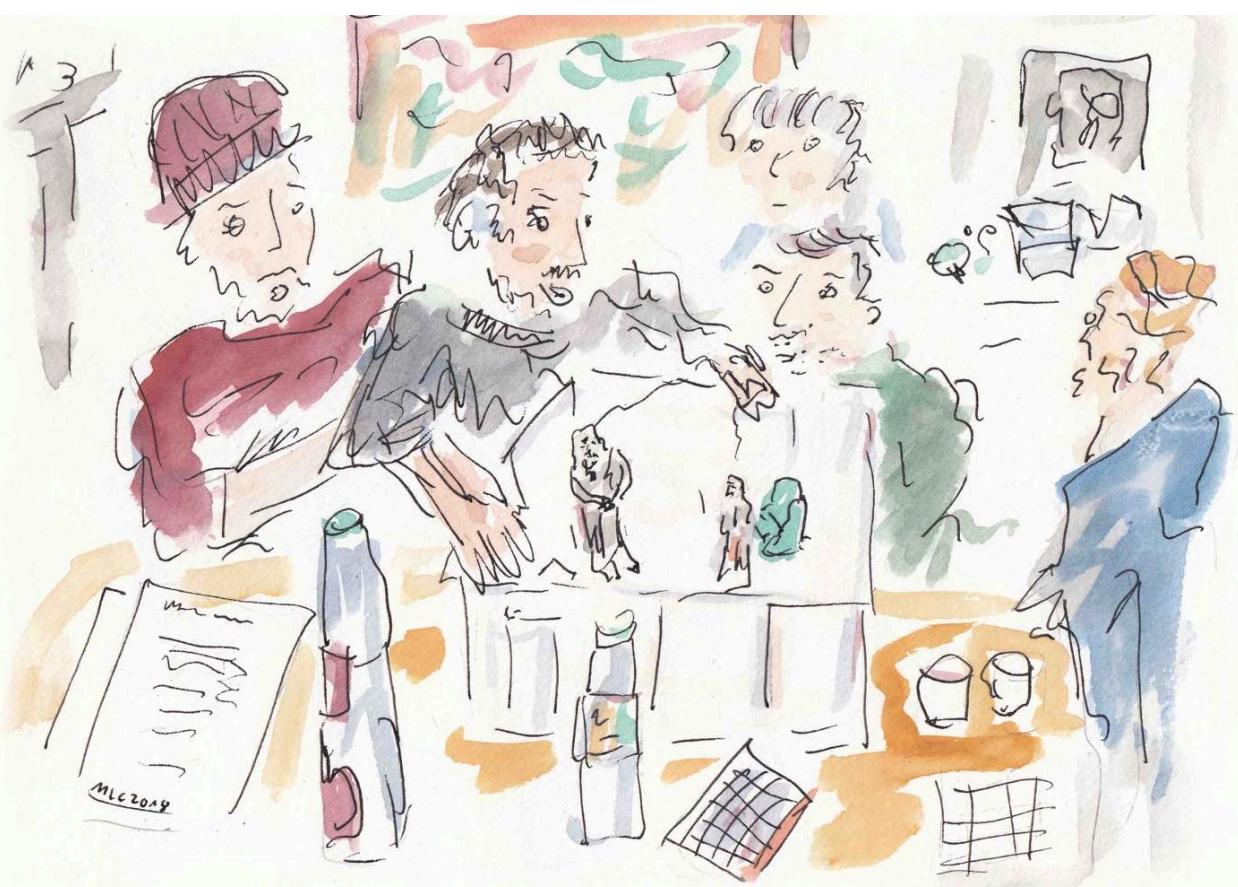

Credit: Maxime Le Calvé

When I enter the kitchen that morning, a catering service has already brought breakfast. The team is gathered around a cardboard model, a white box, in which paper figures represent the actors. They have had several working meetings to come up with a staging beforehand. The director again unfolds meticulously the steps through which the different elements will be filmed during that day. The filming should compose the spontaneity of the action that is to be filmed - a scene of interaction between mother and son with unwritten dialogue, during which the artist will produce a work of art in front of the cameras. A model has been made to predict by materialization the path she will take at each appearance - these trajectories are entirely scripted. Robin, the director, rehearses things once again, he is the one who keeps things in hand and the information in his head. The second director remains silent - he has been scheduled as a back-up. 


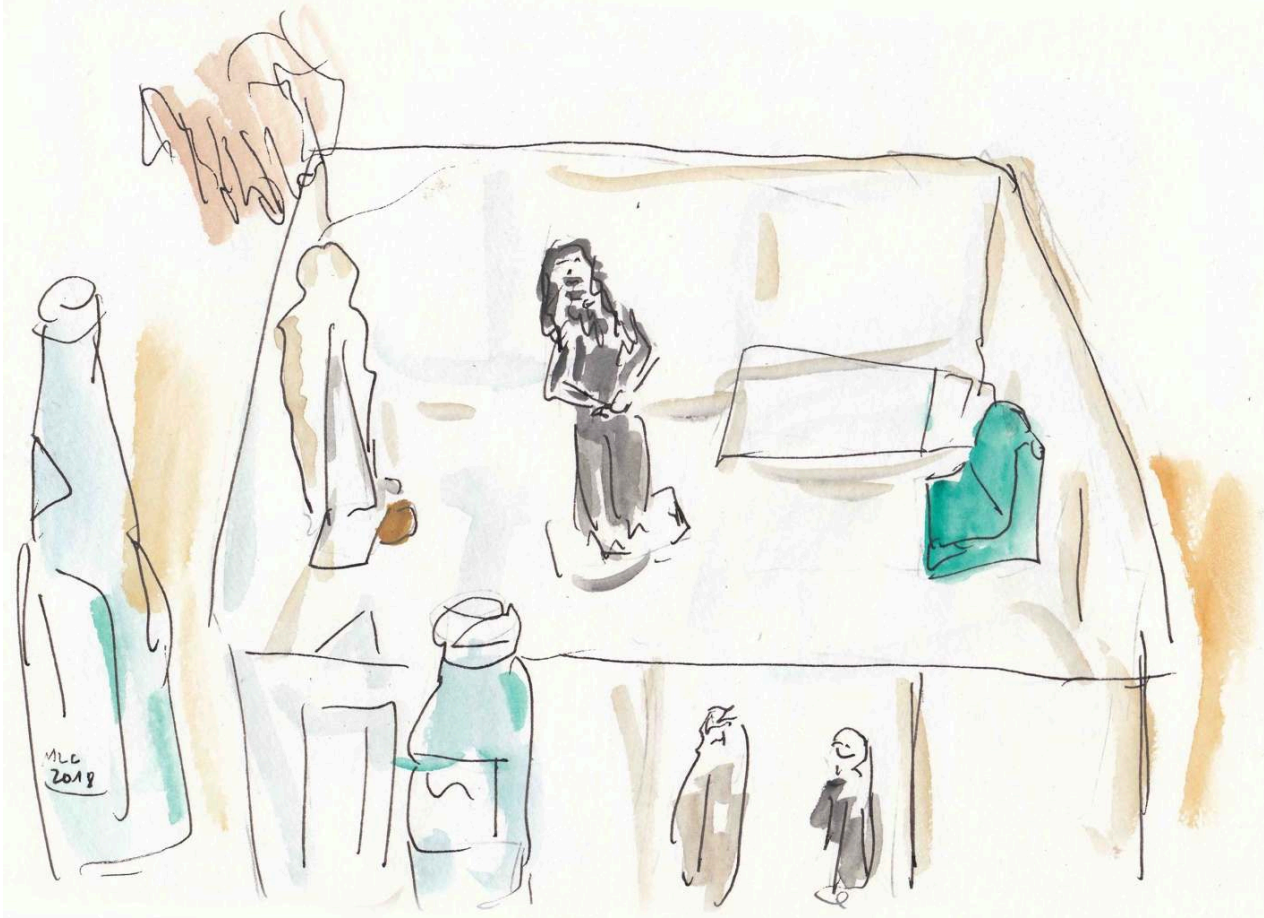

Credit: Maxime Le Calvé identical boxes - allowing the crew to make two takes of the main scene. Each time the artist will paint on the white walls - as this action changes the set in a performance that has to be captured on the spot, in a sequence shot. This set, which during the shooting becomes a pictorial work and an art installation, will be transported into the museum space to lend extra presence to the virtual re-enactment that will be offered to the viewer. Robin prepares Brigitte before her entrance, repeating to her step by step all the steps and movements that are expected. The lady nods with her usual acuity, she will not make any mistakes. 


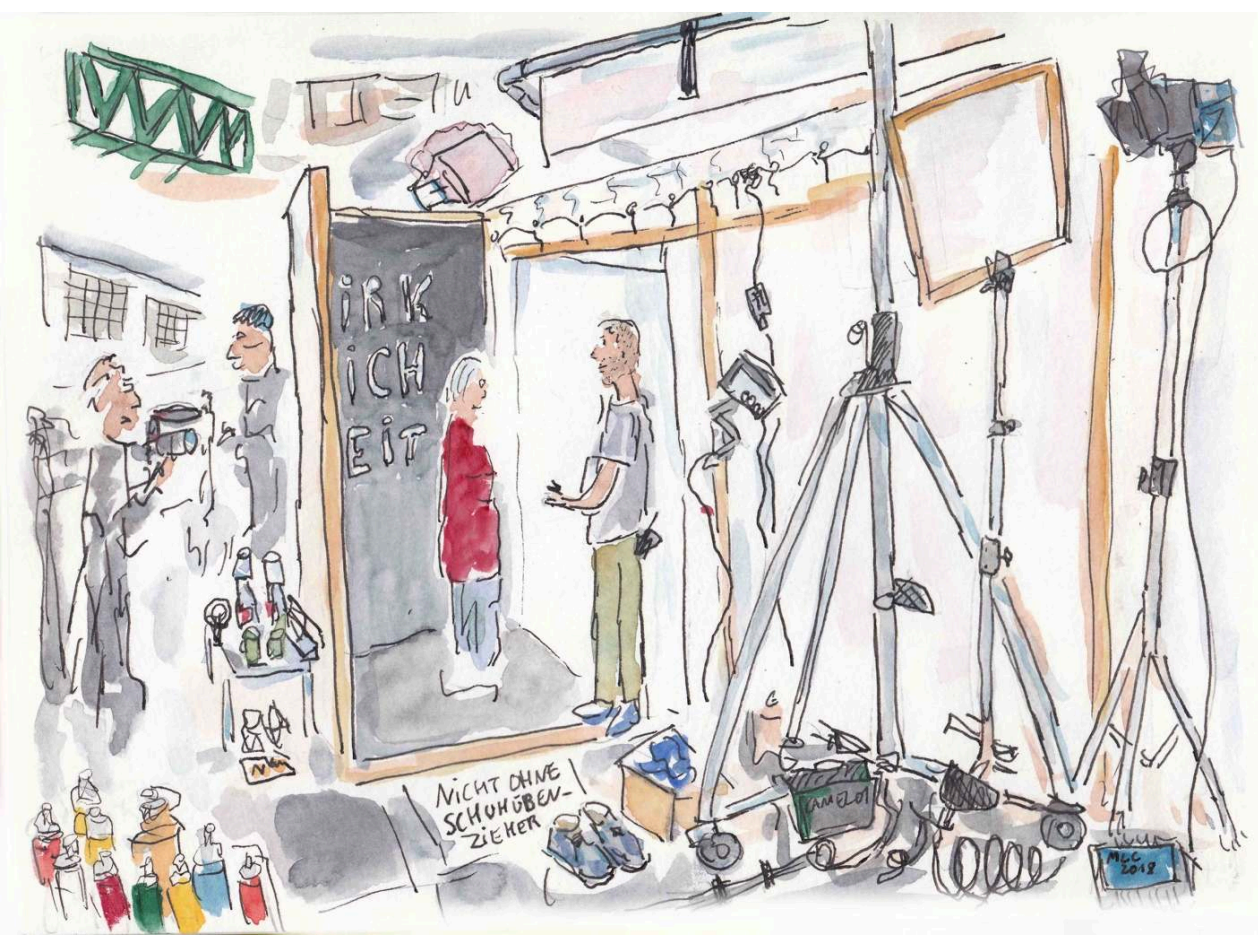

Credit: Maxime Le Calvé

At the start of this chain of action, there was this cardboard model. During the preparatory meetings, the model has allowed them to play and multiply the versions of the work, in order to find the one that puts everyone in accord, the one that, because it is "right," will allow all the conditions necessary for the production to be met. ${ }^{89}$ This allows the play between humans and things to be spatialized, a play articulated around the proxemic dimension (at the moment when I'm editing this text, we are constantly reminded of "social distance" - proxemics is the field of study of social distances) -a dimension that has been noted by others to be essential for this type of virtual reality narrative making (Pope et al. 2017). The morning briefing format allows the work to access a transient form of existence: this is how things should be. During this final small-scale rehearsal, the scripted action is imprinted into the various participants' memory, which allows to review in a last participatory round the unforeseen problems that could come up-this is made possible by the material anchoring provided by the model, and with it the unfolding of a "second performance" - the preparation of the filming itself. ${ }^{10}$ 




Credit: Maxime Le Calvé

During the production process of this work in VR, a team is articulated and active around the actors and around the camera. ${ }^{11}$ The camera, along with a microphone, is installed in the middle of the box. Illuminated panels are also installed directly on its tripod, to add light and counterbalance the shadow it casts in the middle of the room, so as to completely erase its presence. The $360^{\circ}$ camera, with its eight fisheye lenses, is like a giant insect in the middle of the stage, around which everything is organized. The presence mediated by the camera, like that of surveillance cameras or drones, is not unsettling - it is up to the director to turn it into his eye, the tool through which the situation and the atmosphere are captured. 
Illustration 8: Excerpt from the filming, Brigitte hands a lollipop to Jonathan. Behind her is an inscription in paint: Wirklichkeit [reality]

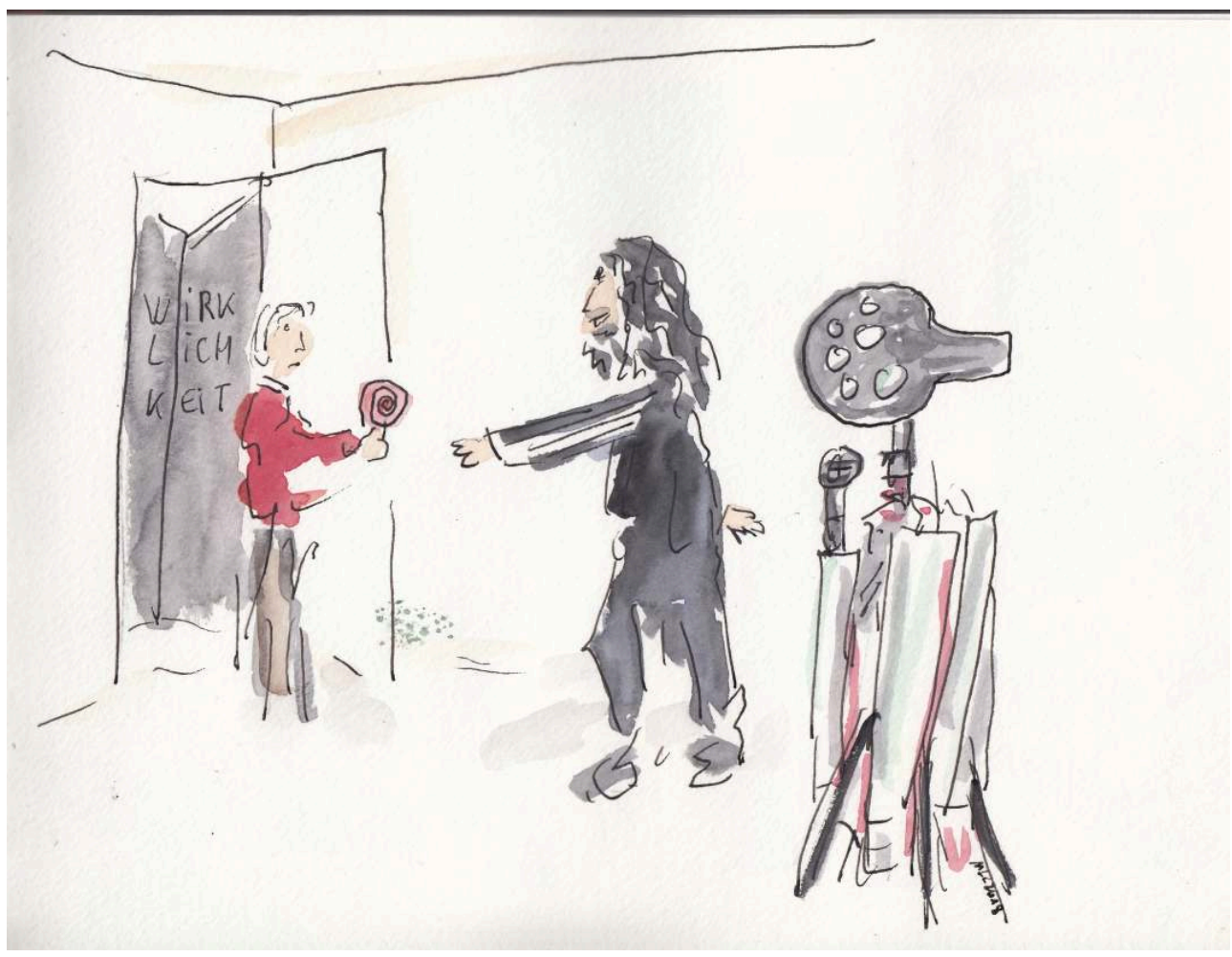

Credit: Maxime Le Calvé

For the viewer in VR, the camera fades away. But for the actors, this presence is felt as the virtual spectator. The relationship between the artist and his mother is not feigned: the micro-gestures, the daily words, the attitudes, are indeed those of their intimacy which feels a bit overplayed and recomposed. The eight "fish eyes" are constantly watching them, and behind them, the operator, the director and the audience. The artist and his mother are used to the presence of the camera - they routinely employ professional video artists who produce content for their website. While Meese favours the format of speech or manifesto reading in his performances, the act of painting or the relationship with the mother and son are regularly staged on his YouTube channel and in his public appearances. When he is performing for the camera - for the slightest interview - the artist changes his attitude and his character takes over. Brigitte often says that she 'doesn't recognize her son' when he is on stage. In this exercise, however, during which Meese remains in the role of the loving and obedient son, she remains in control of the situation. The director has chosen to create an artificial situation that amplifies the presence of the artist's mother during the creative act by multiplying her in the image, showing her in several positions at once. 
Illustration 9: From the control room, previewing the images

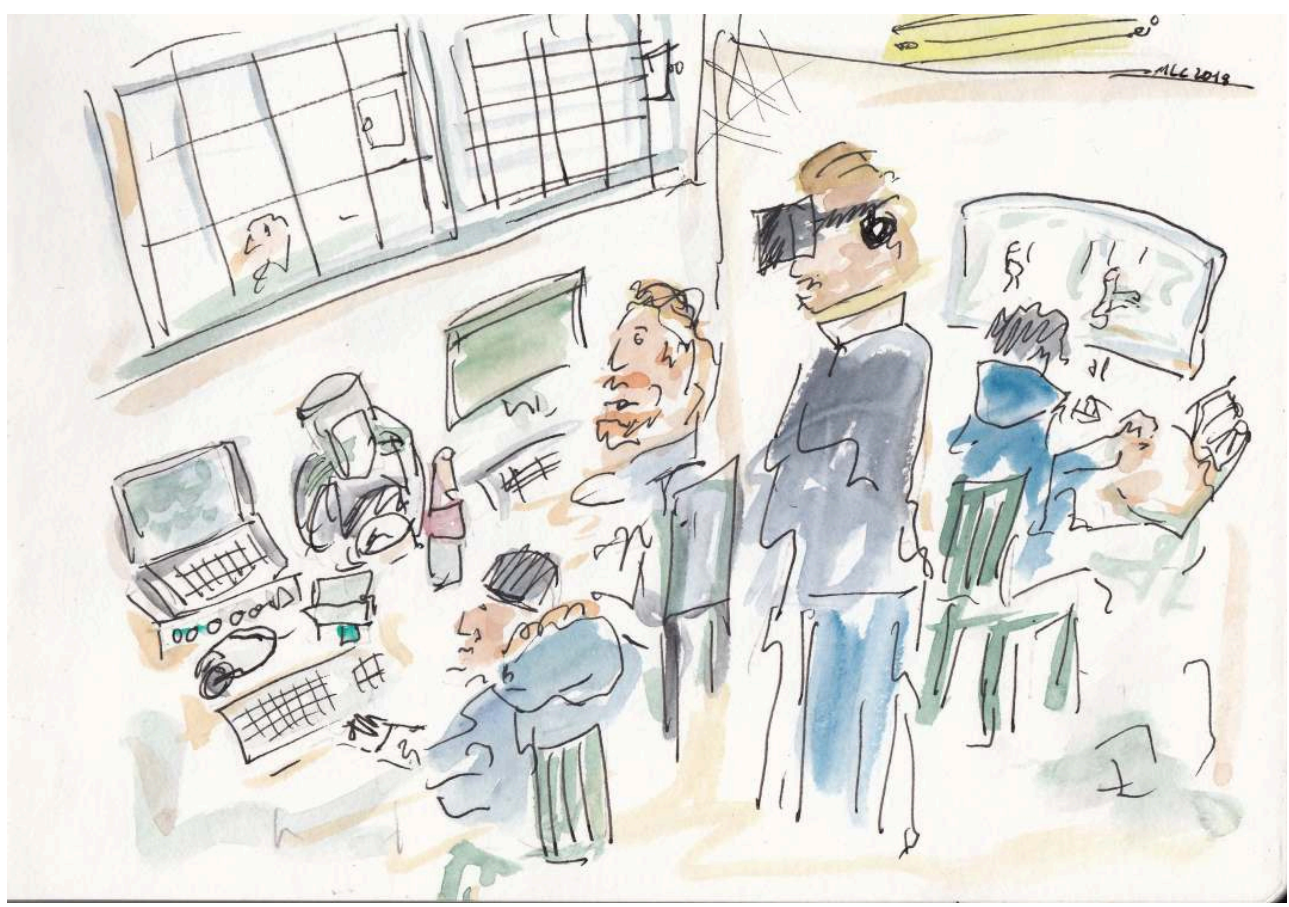

Credit: Maxime Le Calvé

In a small office adjoining the studio, the operators are sitting with their equipment: the sound engineer, on the left, the camera operator, on his right. On the far right of the drawing, an editor and his workstation with an extra-large screen. The camera operator is not behind the camera but detached, in a side room, as is the director, who also completely disappears during the scene so as not to appear in the images. During the shooting, he can put on a virtual reality headset to watch the scene from the camera's point of view. 
Figure 10: Philippe, the $360^{\circ}$ camera operator in front of his workstation, adjusting the brightness

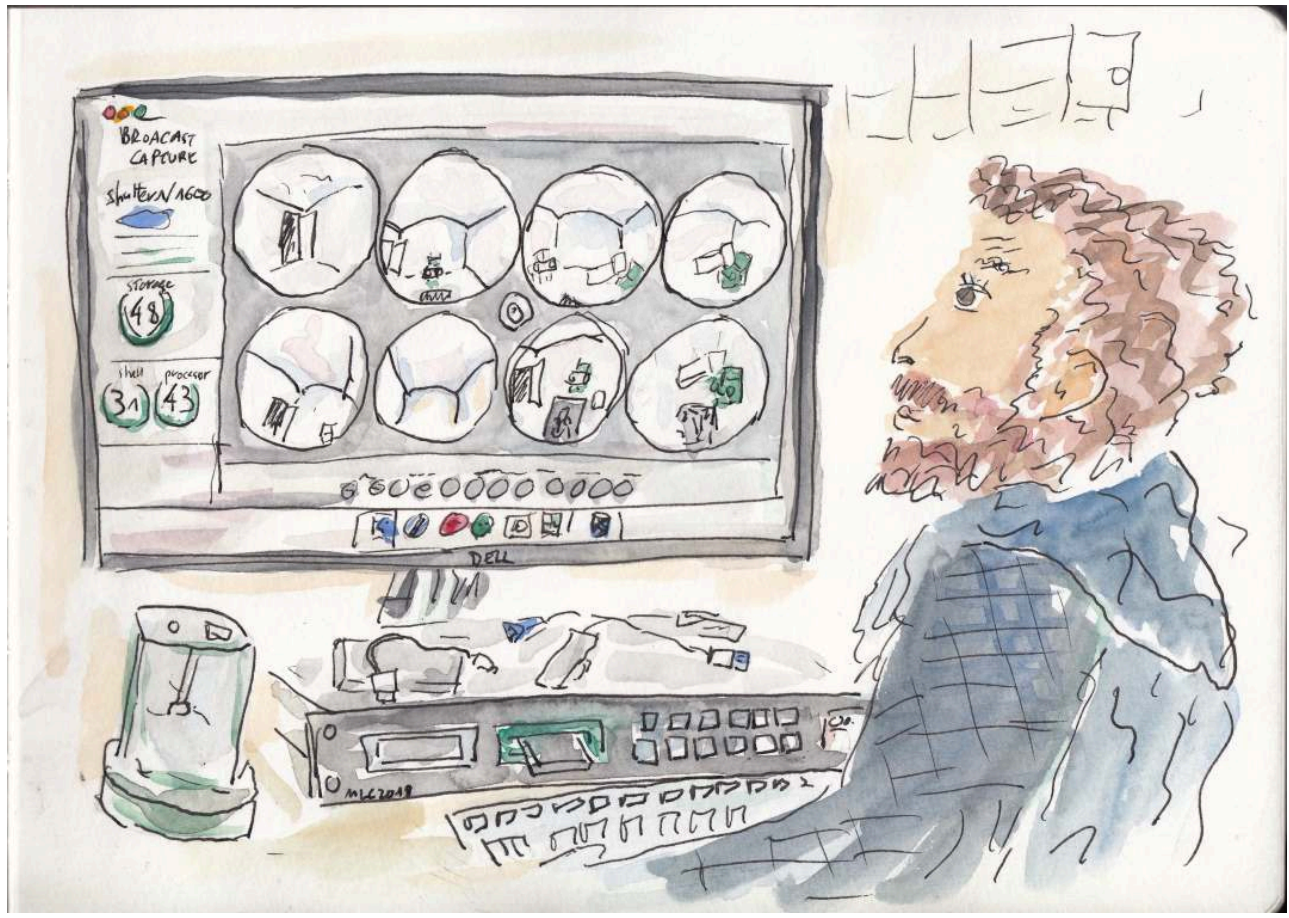

Credit: Maxime Le Calvé

An operator is in charge of the photography - here, however, there is no framing, no change of focus. The main problem is the homogeneity of the lighting, so that the signals can be stitched together into one image sphere. Each of the eight sensors must receive just enough light to ensure that their footages are uniformly exposed. The fragmentation of the image must disappear here: the aim is to make the shot as neutral as possible, to become a single field of view. The lighting, which is mostly done from the outside, is adjusted according to Philippe's needs, who remains seated behind the screen. From this position he controls the recording of data on an interface specially designed for VR. The data is recorded on the fly on hard disks that are regularly changed: the mass of data generated is very large by the standard of digital movie production. 


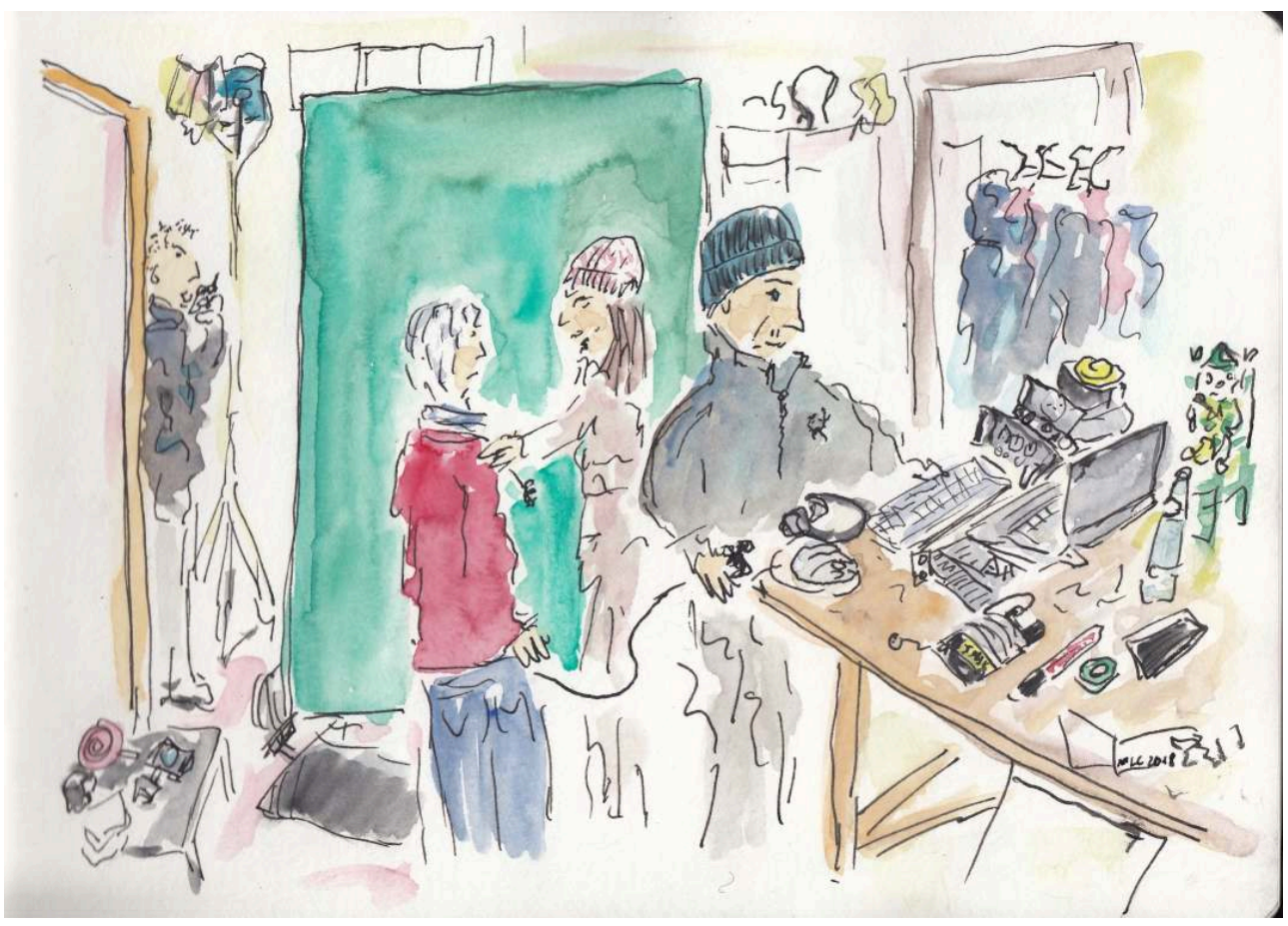

Credit: Maxime Le Calvé

The sound engineer places a lapel microphone on Brigitte Meese. The sound is recorded on several tracks: four of them are dedicated to multidirectional ambient sound. This special microphone is mounted on the $360^{\circ}$ camera stand. The visual perception of the filmed events must be accompanied by an auditory perception, also in $360^{\circ}$. In order to amplify the presence of the characters and the quality of the voice recording, this ambient sound recording is mixed with voice recordings taken directly from the actors' bodies. These information streams are transmitted over the air and recorded on a station located near the video operator. In post-production, the sound man will have to recompose the soundscape from the perspective of the central microphone, in order to reinforce the ambient sounds with the voices.

A difficulty well identified by specialists in virtual reality experiences is that of drawing the viewer's attention to elements that are important to the narrative. Sound is called upon to contribute - immersed in the sonic atmosphere, the viewer is kept in the presence of elements that are not in his or her line of sight by their sonic emanations. The creaking of the door, a sound that did not exist during filming, was added in postproduction to draw the viewer's attention to the arrival of a new Brigitte in the scene, who would have gone unnoticed if she had only manifested herself through her voice. 
Illustration 12: Watching the rushes at the end of the day, in front of images that have been prepared to give an idea of the final result

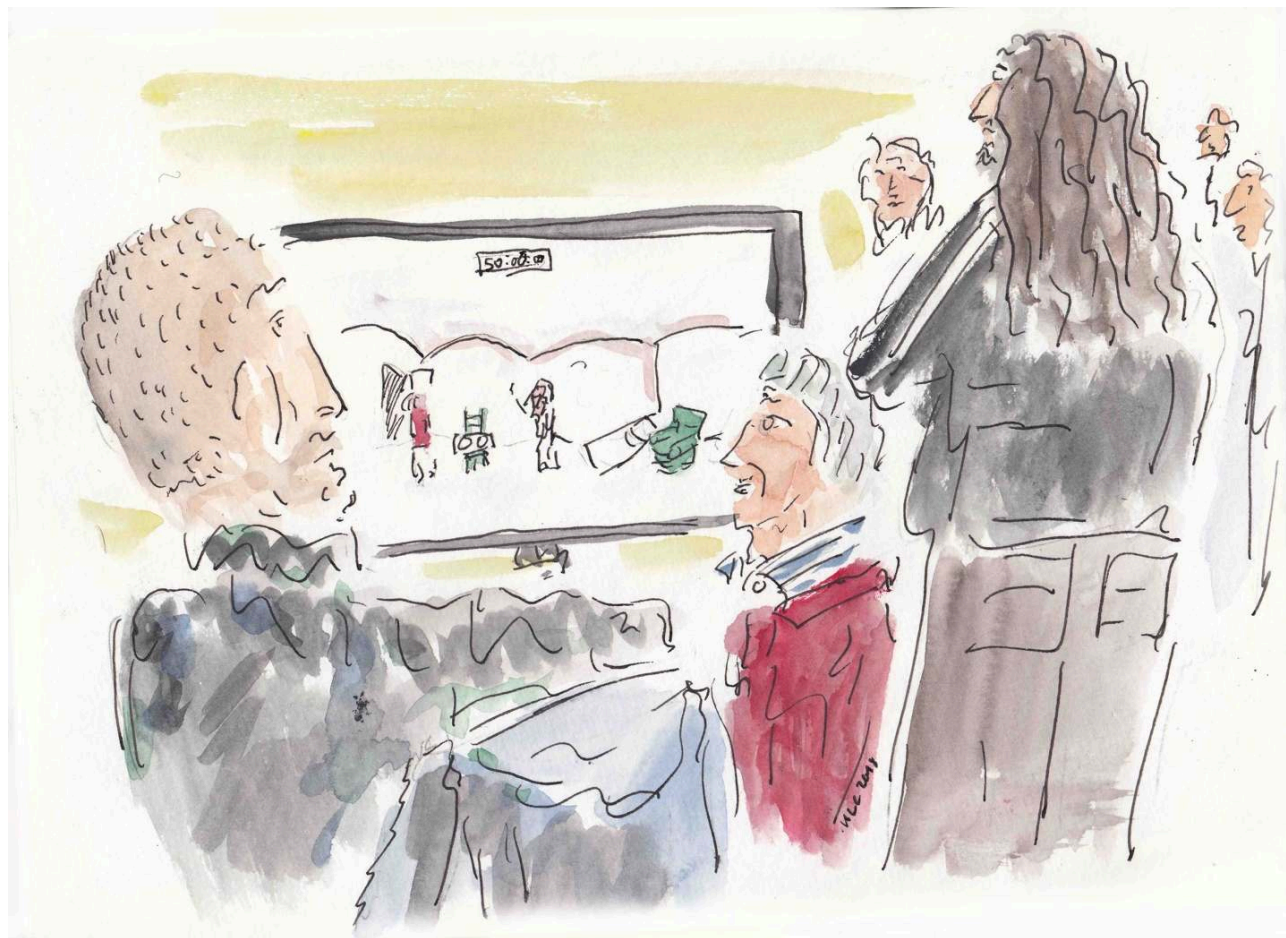

Credit: Maxime Le Calvé

At the end of the day, René, the director, invites us to sit in front of the editing station to view the work that has been done. One person makes a first draft as the shooting continues, to provide an initial impression of what the final result will look like with the material. The directors want to make sure at this early stage whether they can use the footage. The editor does not work with a headset, but with a panoramic flat screen. The $360^{\circ}$ video appears unfolded like a long ribbon. The four walls of the box appear next to each other. It takes a while to get used to it, but you soon get the idea: Brigitte and Jonathan look at the results of the first filming sessions, much amused. 


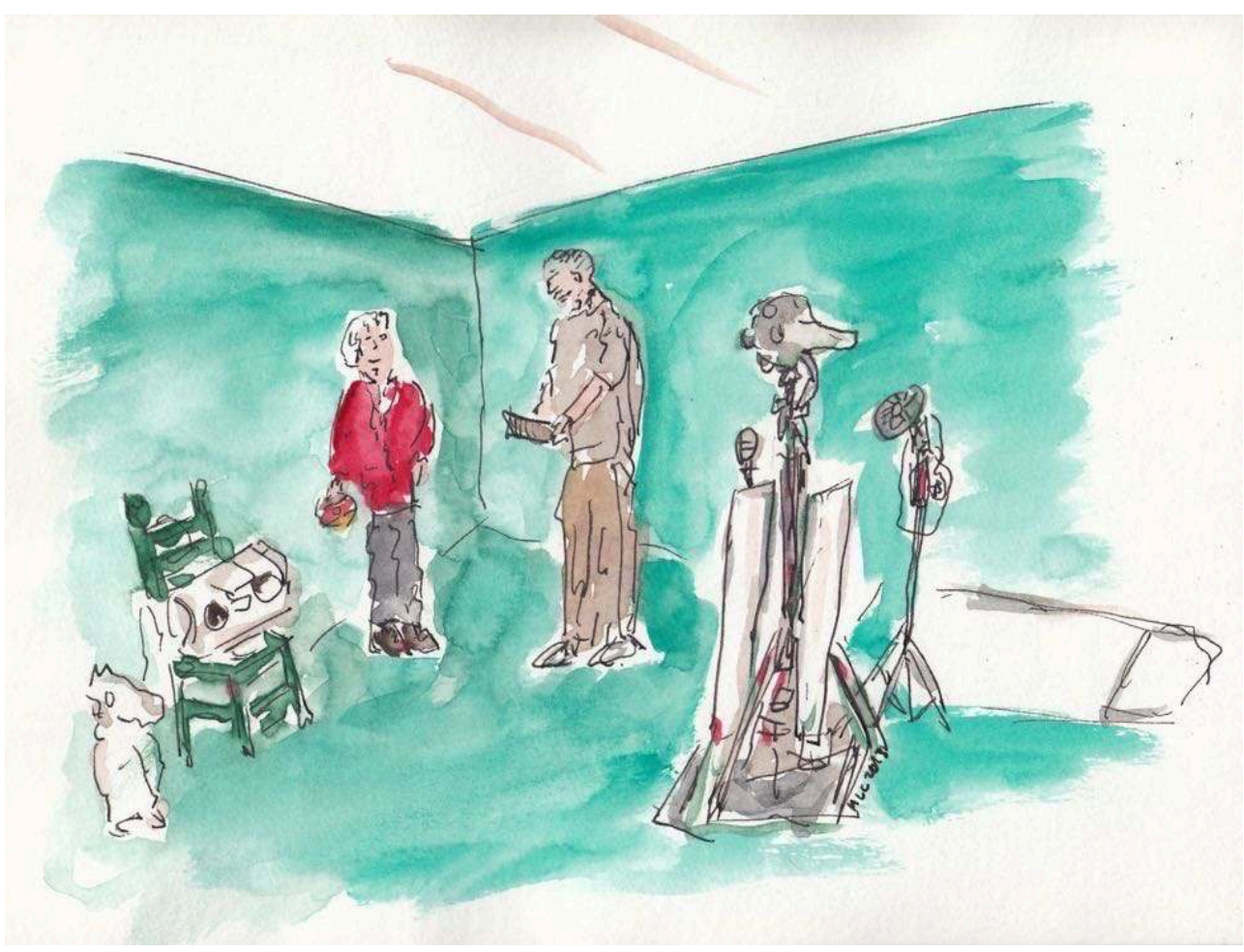

Credit: Maxime Le Calvé

After the first two takes, during which two white boxes were used as a canvas by the artist, one of the two boxes was covered with green paper in order to serve as a neutral setting for the actions of Brigitte's avatars. The images captured by the camera will then be inserted into the sequence shot with Jonathan Meese. The difficulty is to convey presence to the other Brigittes who are in the room at all times: they will appear in the virtual space, but their ghostly presence must be avoided so that there are no collisions or strange interactions in the editing. René guides her through this work by rehearsing each sequence step by step with her before starting the recording.

Illustration 14: Shooting the final scene
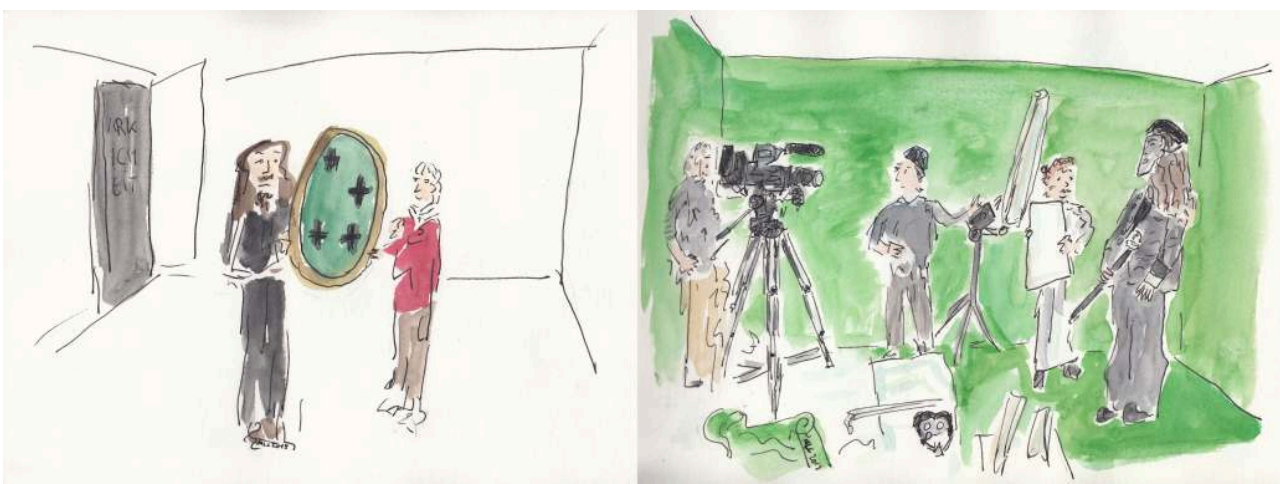

Credit: Maxime Le Calvé

Final scene, the mother and son look at the camera and present a mirror to the virtual spectator. This effect works because the director can accurately anticipate the position of the viewer's head: the mirror will seem to reflect the character he is portraying in 
the scene. The mirror that has been used as a prop is an empty frame, a simple panel with markers (fig. 14a). The image that appears on it is shot separately and inserted in post-production. A conventional camera is used to film this shot: Jonathan Meese is dressed in a Richard Wagner costume and wears a cardboard mask with the composer's face printed on it (fig. 14b). He does several takes, trying out different postures. The light here is corrected with a spotlight and reflector. This final scene was shot last, closing the two days of production on site in Meese's atelier.

\section{Conclusion: Dealing with atmospheres in VR}

40 I have chosen to describe the work in progress because certain "presences" are more explicitly manifested there than they are in the finished work. These presences - the technical mediations, the virtual existence of the viewer and the complex aura of Meese's character - are pivotal to the shaping of the work. How are the atmospheres invited to manifest themselves in the device prepared for this purpose? How is the experience and diffuse attention of the virtual spectator, which becomes the central concern, handled by the team? Without making any aesthetic judgement on the work itself, I have described the actors grappling with multiple decisions made upstream, some already well established and incorporated in the technical devices, others more audacious and elaborated in the dramaturgical process. In this concluding section, I attempt to give these dealings with atmospheres their rightful place in the process of producing the work.

41 During the filming of the $360^{\circ}$ video, the workflow involves a procedure that is particularly fussy in some respects - controlling the lighting, adjusting the remotely controlled visual and sound capture devices, sequencing the shots, placing the bodies in the space and controlling their trajectories, processing the camera and audio files on the fly. Some members of the team are able to control and adjust the device by sensitively experiencing a glimpse of the work as it is being captured. By looking at the monitors and regularly donning the virtual reality headset, the director and operators can fine-tune the settings and spot perceptual problems that would make a take unusable. Through this regular contact with what is happening at the "end of the line", they ensure the integrity of the materials that will be used to accomplish the transposition of the atmosphere of a live performance to that of a digital performance - ensuring a certain continuity and homogeneity that would otherwise disrupt the viewer's experience. These observations allow us to situate the work in a web of infrastructure, a "relationship between work, practice and technology" that "fades into the background until it disappears" (Star and Ruhleder, 2010, p. 117). The whole apparatus which makes the work visible to the public also belongs to this infrastructure, which is the subject of this paper: the logistics of production, but also the communication around the work, its distribution and, in particular, the presentation of the work in the museum.

The status of other elements of this chaine opératoire, however, seem less clear: what about the dialogues of the performance, the brush stroke on the wall, or the interaction between Jonathan Meese and his mother? Their indeterminacy makes me think that these elements are ultimately the most stable and solid components of this operative chain - they make the atmosphere of spontaneity of the performance, and this is precisely the phenomenon that the technical device is seeking to invite. This theatrical 
atmosphere is thus based on a living, intimate and existential relationship, which, when invited to unfold in the controlled space of the filming, takes on a new momentum in this technical process. As our colleagues have recently written about the staging of urban atmospheres:

Atmospheres are not simply about fragmentation into individualized or solipsistic experiences of a world that comes into being through a particular atmosphere. Atmosphere is equally about the social intersections of people, places and things that unfold through the staging of more or less explicit power struggles and affective manipulations. (Bille, Bjerregaard and Sørensen, 2020, p. 38)

The atmosphere staged with the VR device cannot, therefore, be reduced either to the solipsistic subjective perception of the spectator, nor to that of an "aura" relative to the sole person of the artist. That atmosphere is an "intersection" based on "power relations" and "affective manipulations". This staging assumes that the performance, however radical and spontaneous, obeys the demands of each of the human and nonhuman actors - technicians, machines, institutions. Subjected to what he calls a "dictatorship" in his work, Jonathan Meese also knows how to stage his process in order to share his experience of creation, along with the power games and the ambiences that they create. The role of the artist is to remain in action, and to obey it as he obeys his mother, to use an analogy he continues to exemplify in this work. There is no negotiation with that atmosphere: the atmosphere is in control. His selfproclaimed and irreverent docility refers to a way of acting that delegates decisions to technical and institutional infrastructure, to the activity of materials, to the path from line to brush, and more generally to the contingencies of situations. It is the power of this atmosphere, the one attached to the artist's creative process, that motivated the producers to propose this new artistic experimentation. The process of production in VR and the content of the performance itself are thus articulated and knitted together in a very tight way. The filming thus proceeds smoothly - Jonathan Meese and his mother capture and are captured by the artistic and technical device, and with them, the atmospheres they invoke in their action - maternal tenderness, energy and benevolent acceptance of contingencies, as well as a certain strangeness laced with humour.

In "Atmosphere as the fundamental concept for a new aesthetic" Gernot Böhme argues that the artist ultimately works with atmospheres rather than actual materials (2018, p. 36). This argument is confirmed here to some extent - everything in this creation is about making atmosphere the basis of the collective work. The team constantly strives to match the experience of the filming with the experience of the virtual spectator, whose omnipotent presence and diffuse attention is contained in this eight-eyed camera with four microphones. Yet precisely because the whole process of production in VR is organized around and through a certain atmosphere that has incompressible demands (and generosity), Böhme's argument is unexpectedly inverted: it is no longer the artist who works with the atmosphere, but it is the atmosphere that works through the artist, the director and his crew. Borrowing on the legacy of Richard Wagner's Parsifal, Brecht's experiments and the works of the artists of the Fluxus movement, the performed atmosphere triggers indeterminacy and ambiguity rather than delivering a clear-cut message to the spectator. This fits well with the chosen medium. VR allows for that same floating, a permanent flickering between the presence and absence of the spectator in the situation and in what is being told - just like what happens also, in another way, through ethnographic drawings. 
The author acknowledges the support of the Cluster of Excellence "Matters of Activity. Image Space Material " funded by the Deutsche Forschungsgemeinschaft (DFG, German Research Foundation) under Germany's Excellence Strategy - EXC 2025 - 390648296.

\section{BIBLIOGRAPHY}

Atkinson, Paul. 2006. Everyday Arias: An Operatic Ethnography. Lanham, MD: Altamira Press.

Bailenson, Jeremy. 2018. Experience on Demand: What Virtual Reality Is, How It Works, and What It Can Do. 1st edition. New York: WW Norton \& Co.

Bille, Mikkel; Bjerregaard, Peter \& Flohr Sørensen, Tim. 2020. Staging Atmospheres: Materiality, Culture, and the Texture of the in-Between. Emotion, Space and Society, 15. p. 31-38.

Böhme, Gernot. 1993. “Atmosphere as the Fundamental Concept of a New Aesthetics.” Thesis Eleven 36 (1): p. 113-26. https://doi.org/10.1177/072551369303600107.

Boisvenue, Jean-François. 2012. Darstellung und Wirklichkeit in Der Idiot und Die Dämonen, zwei Dostojewski-Bearbeitungen von Frank Castorf für die Volkbühne Berlin [online]. Available online at: https://papyrus.bib.umontreal.ca/xmlui/handle/1866/6299.

Brey, Philip. 2014. The Oxford Handbook of Virtuality. In: Grimshaw, Mark (Ed.). The Physical and Social Reality of Virtual Worlds. Oxford: Oxford University Press. p. 42-54. https://doi.org/10.1093/ oxfordhb/9780199826162.013.029.

Causey, Andrew. 2016. Drawn to See: Drawing As an Ethnographic Method. Toronto: University of Toronto Press.

Clearwater, Bonnie. 2010. Jonathan Meese: Sculpture. North Miami, Fla: Museum of Contemporary Art North Miami.

Cummings, James J. \& Bailenson, Jeremy N. 2016. How Immersive Is Enough? A Meta-Analysis of the Effect of Immersive Technology on User Presence. Media Psychology, 19 (2). p. 272-309. https://doi.org/10.1080/15213269.2015.1015740.

deLahunta, Scott. 2002. Virtual Reality and Performance. PAJ: A Journal of Performance and Art, 24 (1 [70]). p. 105-14. https://doi.org/10.1162/152028101753401839.

Eikmeyer, Robert. 2015. Kunst = Kunst. Karlsruhe: Staatlichen Hochschule für Gestaltung.

Favero, Paolo. 2018. The Present Image: Visible Stories in a Digital Habitat. Cham, Switzerland: Palgrave Macmillan. Available online at: https://search.ebscohost.com/login.aspx? direct=true\&scope $=$ site $\& d b=$ lebk $\& d b=$ nlabk\&AN=1641998.

Fischer-Lichte, Erika. 2004. Ästhetik Des Performativen. Berlin: Suhrkamp.

Fischer-Lichte, Erika.. 2008. The Transformative Power of Performance: A New Aesthetics. Abingdonon-Thames:Taylor \& Francis.

Goddard, Michael N. 2021. Genealogies of Immersive Media and Virtual Reality (vr) as Practical Aesthetic Machines. In Herzogenrath, Bernd (ed.). Practical Aesthetics. London; New York: Bloomsbury Academic. p. 171-82. 
Grau, Oliver. 2003. Virtual Art: From Illusion to Immersion. Cambridge, Mass.: MIT Press.

Heim, Michael. 1994. The Metaphysics of Virtual Reality. Reprint édition. New York: OUP USA.

Hinz, Melanie \& Jens Roselt. 2011. Chaos und Konzept: Proben und Probieren im Theater. Berlin: Alexander Verlag.

Laborde, Denis. 2008. L'opéra et Son Régisseur. Notes Sur La Création d'une CEuvre de Steve Reich. Ethnologie Française, 2008 (1). p. 121-30.

Laborde, Denis. 2009. “Faire La Musique. Enquête Sur Une Création.” Appareil, no. 3. http:// appareil.revues.org/850.

Latour, Bruno. 1994. On Technical Mediation. Common Knowledge, 3 (2). p. 29-64.

Le Calvé, Maxime. 2015. Ethnographie dans l'espace de la 'Dictature de l'Art' de Jonathan Meese. Comment bien 'laisser faire ce qui arrive.' In: Golsenne, Thomas \& Ribault, Patricia (eds.).

Techniques \& Culture. Revue semestrielle d'anthropologie des techniques, no. 64 (December). https:// doi.org/10.4000/tc.7591.

Le Calvé, Maxime. 2017. Grenzgänger Der Kunst: Die Sammlung Als Plurales Medium in Der Künstlerischen Praxis von Jonathan Meese. Paragrana 26 (November). https://doi.org/10.1515/ para-2017-0026.

Le Calvé, Maxime. 2018. Invocations antagonistes : les atmosphères condensées de l'artiste Jonathan Meese. Communications, no. 102 (May). p. 153-67. https://doi.org/10.3917/commu. 102.0153 .

Le Calvé, Maxime \& Gaudin, Olivier. 2019. Depicting Berlin's Atmospheres: Phenomenographic Sketches. Ambiances. Environnement Sensible, Architecture et Espace Urbain, no. 5 (December) [online]. https://doi.org/10.4000/ambiances.2667.

Lehmann, Hans-Thies. 2006. Postdramatic Theatre. $1^{\text {st }}$ ed. Milton Park, Abingdon, Oxfordshire: Routledge.

Lemonnier, Pierre. 2004. Mythiques chaînes opératoires. Techniques \& Culture. Revue semestrielle d'anthropologie des techniques, no. 43-44 (December). https://doi.org/10.4000/tc.1054.

Lemonnier, Pierre. 2011. L'Étude Des Systèmes Techniques. Techniques \& Culture, no. 1. p. 47-67.

Oberender, Thomas. 2004. Mehr Jetzt Auf Der Bühne. Sehen Heißt Entscheiden: Theater Und Video. Theater Heute, no. Theatre und Video (April). p. 19-26.

Ohrt, Roberto. 2014. Dr. No Private Meese and the Masks of History. In Pump up the Vampire, Pump up the Vampire, Pump up the Vampire, Smell!, translated by Fergus Mason. Glasgow: Glue Factory. p. 8-21

Pope, Vanessa C.; Dawes, Robert; Schweiger, Florian \& Sheikh, Alia. 2017. The Geometry of Storytelling: Theatrical Use of Space for 360-Degree Videos and Virtual Reality. In Proceedings of the 2017 CHI Conference on Human Factors in Computing Systems - CHI'17,. Denver, Colorado, USA: ACM Press. p. 4468-4478 https://doi.org/10.1145/3025453.3025581.

Roselt, Jens. 2008. Phänomenologie des Theaters. Auflage: 1., Aufl. München: Fink, Wilhelm. Schechner, Richard. 1985. Between Theater \& Anthropology. Philadelphie: University of Pennsylvania Press. http://gen.lib.rus.ec/book/index.php? md5=4d7d5a18d0a62c2cebfac905353445a6. 
Schmitz, Hermann. 2011. Emotions Outside the Box - the New Phenomenology of Feeling and Corporeality. In Owen Müllan, Rudolf \& Slaby, Jan (eds.). Phenomenology and the Cognitive Sciences 10 (2). p. 241-59. https://doi.org/10.1007/s11097-011-9195-1.

Schmitz, Hermann. 2018. Les sentiments comme atmosphères. Translated by Jean-Louis Georget and Philippe Grosos. Communications, no. 102. p. 51-66. https://doi.org/10.3917/commu.102.0051.

Siegenthaler, Fiona. 2013. Towards an Ethnographic Turn in Contemporary Art Scholarship. Critical Arts: South - North Cultural and Media Studies, 27. p. 737-52.

Slater, Mel \& Sylvia Wilbur. 1997. A Framework for Immersive Virtual Environments Five: Speculations on the Role of Presence in Virtual Environments. Presence: Teleoperators and Virtual Environments 6 (6). p. 603-616. https://doi.org/10.1162/pres.1997.6.6.603.

Star, Susan Leigh \& Karen Ruhleder. 2010. Vers une écologie de l'infrastructure. Revue d'anthropologie des connaissances Vol 4, $\mathrm{n}^{\circ} 1$ (1). p. 114-161.

Stein, Christian. 2016. Virtual Reality Design: How Upcoming Head-Mounted Displays Change Design Paradigms of Virtual Reality Worlds, no. 1: 34. MediaTropes, Volume 6, Number 1 (34). p. $52-85$

Steuer, Jonathan. 1992. Defining Virtual Reality: Dimensions Determining Telepresence. Journal of Communication 42 (4). p. 73-93. https://doi.org/10.1111/j.1460-2466.1992.tb00812.x.

Sumartojo, Shanti \& Sarah Pink. 2019. Atmospheres and the Experiential World: Theory and Methods. Ambiances, Atmospheres and Sensory Experiences of Space. London New York, NY: Routledge.

Tinius, Jonas. 2017. “Anthropological Observations on artistic subjectivation and institutional reflexivity: the theatre project Ruhrorter with refugees at the Theater an der Ruhr." In Applied Theatre: Rahmen und Positionen, edited by Matthias Warstat, Florian Evers, Kristin Flade, Fabian Lempa \& Lilian Katharina Seuberling, p. 205-35. Theater der Zeit Recherchen 129. Berlin: Theater der Zeit.

Weiler, Christel \& Roselt, Jens. 2017. Aufführungsanalyse: Eine Einführung. 1st ed. Tübingen: UTB.

Wendler, Reinhard. 2013. Das Modell zwischen Kunst und Wissenschaft. München: Wilhelm Fink Verlag.

Woletz, Julie. 2018. Interfaces of Immersive Media. Interface Critique Journal [online]. Available online at: https://interfacecritique.net/journal/volume-1/woletz-interfaces-of-immersivemedia/.

Yaneva, Albena. 2005. Scaling Up and Down: Extraction Trials in Architectural Design. Social Studies of Science 35 (6). p. 867-94. https://doi.org/10.1177/0306312705053053.

Youngblood, Gene. 1970. Expanded Cinema. 1st ed. New York, N.Y: Dutton.

\section{NOTES}

1. Mère et fils: La réalité face à l'art. (L'A.V.E.N.I.R. de l'infini) (2017) $360^{\circ}$ video and installation, directed by René Päpke and Robin von Hardenberg; concept: Jonathan Meese; dramaturgy: Henning Nass, produced by Studio Kobald in partnership with INVR for ARTE 360 and the Immersion programme of the Berliner Festspiele. "Digital Productions - Brigitte \& Jonathan Meese: A Mother and Son - ARTE," accessed September 11, 2018, https://www.arte.tv/sites/ webproductions/brigitte-jonathan-meese-une-mere-et-son-fils/. 
2. You can also watch the video on an ordinary screen and use the mouse to change the viewing angle throughout the video - this medium greatly restricts the experience, but it was useful as a refresher for me while writing this article.

3. The work of ethnographers Paul Atkinson (2006) and Denis Laborde $(2008,2009)$ on opera is also one of the few cases in the anthropological literature devoted to this activity; more recently, Jonas Tinius' ethnography on the Ruhr Theatre is noteworthy (2017).

4. For a detailed discussion of the practical issues involved in this method, please refer to the chapter devoted to it in the recent introduction to performance analysis. (Weiler and Roselt, 2017)

5. Characters of children's stories popular in northern Europe, created by the Scandinavian writer Tove Jansson.

6. This is the feeling of an overwhelming majority of my academic interlocutors in France, but also that of some art connoisseurs and critics in Germany.

7. For a synthesis of the legacy of this method and intellectual tradition, see the texts of Lemonnier $(2004,2011)$.

8. I was not invited to attend these preparatory meetings. On the other hand, I have accompanied the team for several years, especially during the production of two operas, so I am familiar with their way of working.

9. On the role of the model in artistic creation, reference can be made in particular to the work of Reinhardt Wendler (2013) and Albena Yaneva (2005).

10. I'm borrowing here the concept of the "second concert" as defined by Denis Laborde (2008)

11. It's a Nokia Ozo camera.

\section{ABSTRACTS}

Picture yourself spending several years studying the artistic activity of a famous contemporary artist. Someday you are told that the artist, Jonathan Meese, is going to produce a work in virtual reality (VR) for the ARTE channel and one of Berlin's leading institutions specializing in immersive artworks, the Berliner Festspiele. In this piece, he will stage his creative process and the intimate sphere of his relationship with the person who puts him to work: his own mother. This performance, filmed in $360^{\circ}$ by an expert technical team, is a perfect opportunity to take a lesson in sensory documentation as well as an exploration of the possibilities offered by this emerging medium. The production team commissioned me to do a series of ethnographic drawings about the production process of this work. Through these images, I depict the process of staging the performance. In this article, I describe a theatrical object "in the making." In the last part, I highlight the specific component related to VR devices in this performance and the mediating effect that this technology imposes on it. This will allow me to show how the production process and the atmospheric dimension of the phenomenon are closely intertwined, and what immersive media can contribute to contemporary thinking on atmospheres in anthropology - and to the topic of ethnographic drawing.

Imaginez que vous consacrez plusieurs années à étudier l'activité artistique d'un célèbre artiste contemporain. On vous annonce un jour que Jonathan Meese, l'artiste en question, va produire une œuvre en réalité virtuelle (VR) pour la chaîne ARTE et l'une des grandes institutions berlinoises spécialisée dans les œuvres d'art immersives, le Berliner Festspiele. Il va y mettre en 
scène son processus de création et la sphère intime de sa relation avec la personne qui le met au travail : sa propre mère. Cette performance, filmé à $360^{\circ}$ par une équipe technique experte, est une occasion rêvée pour l'ethnographe de prendre une leçon de documentation multi sensorielle -et ainsi d'explorer les possibilités offertes par ce média émergent. L'équipe de production me commande une série de dessins sur le processus de production de cette œuvre, qui seront publiés par le blog de l'institution. A l'aide de ces images, je raconte la chaîne opératoire que constitue la captation de la performance-je décris ainsi dans cet article ethnographique un objet théâtral «en train de se faire.» En dernière partie, je mets en valeur la composante spécifique du dispositif VR dans cette performance et l'effet de médiation que cette technologie impose sur celle-ci. Cela me permettra de montrer comment le processus de production et la dimension atmosphérique du phénomène sont étroitement articulés ensemble, et ce que les médias immersifs peuvent apporter à la réflexion contemporaine sur les atmosphères en anthropologie -mais aussi à propos du dessin ethnographique.

\section{INDEX}

Keywords: atmosphere, performance, virtual reality, Jonathan Meese, ethnographic drawing Mots-clés: atmosphère, performance, réalité virtuelle, Jonathan Meese, dessin ethnographique

\section{AUTHOR}

\section{MAXIME LE CALVÉ}

Maxime Le Calvé is a postdoctoral research associate at the Cluster of Excellence "Matters of Activities". As a visual ethnographer, he is making use of drawing as an investigative device, and blogging about his fieldwork using digital sketches. He was trained in general ethnology in Paris Nanterre and has a PhD in social anthropology and in theatre studies, from EHESS Paris and FU Berlin. He is currently teaching multimodal ethnography at Humboldt University in Berlin and writing-as-inquiry within the Open Design Master (Humboldt University/University of Buenos Aires). He is also co-curating the ongoing virtual/physical exhibition Field/Works in Lisbon (ANTART/EASA/FBAUL). More info on: www.maximelecalve.com 